\title{
Claudine GAUTHIER, Saint Jean et Salomé. Anthropologie du banquet d'Hérode
}

Préface de Claude Gaignebet, dessins de Laurent Chiotti. Tours, Éditions Lume, $304 \mathrm{p}$.

Dominique Casajus

\section{(2) OpenEdition}

1 Journals

\section{Édition électronique}

URL : http://journals.openedition.org/assr/21134

DOI : 10.4000/assr.21134

ISSN : $1777-5825$

Éditeur

Éditions de l'EHESS

\section{Édition imprimée}

Date de publication : 31 décembre 2009

Pagination : 75-342

ISBN : 978-2-7132-2218-4

ISSN : 0335-5985

Référence électronique

Dominique Casajus, "Claudine gauthIER, Saint Jean et Salomé. Anthropologie du banquet d'Hérode », Archives de sciences sociales des religions [En ligne], 148 | octobre-décembre 2009, document 148-55, mis en ligne le 03 juin 2009, consulté le 21 septembre 2020. URL : http://journals.openedition.org/ assr/21134; DOI : https://doi.org/10.4000/assr.21134

Ce document a été généré automatiquement le 21 septembre 2020.

(c) Archives de sciences sociales des religions 


\section{Claudine GAUTHIER, Saint Jean et Salomé. Anthropologie du banquet d'Hérode}

Préface de Claude Gaignebet, dessins de Laurent Chiotti. Tours, Éditions

Lume, $304 \mathrm{p}$.

Dominique Casajus

\section{RÉFÉRENCE}

Claudine GAUTHIER, Saint Jean et Salomé. Anthropologie du banquet d'Hérode, Préface de Claude Gaignebet, dessins de Laurent Chiotti. Tours, Éditions Lume, 304 p.

1 Le livre de Claudine Gauthier est consacré à une histoire que nous connaissons tous : la décapitation de Jean-Baptiste, telle qu'elle est racontée dans les Synoptiques. Si Renan y voyait encore «le seul épisode absolument historique de l'œuvre évangélique, tous Évangiles confondus ", les auteurs ultérieurs ont été plus sceptiques (19sqq.). Flavius Josèphe rapporte certes que le Baptiste fut mis à mort sur l'ordre d'Hérode, qui s'effrayait de voir combien la foule semblait « prête à suivre en tout les conseils de cet homme ", mais il ne dit rien des circonstances de cette mise à mort (53). De plus, une jeune fille de sang princier dansant devant les convives d'un banquet a quelque chose d'un peu scabreux aux yeux des historiens d'aujourd'hui. C. Gauthier ne s'interroge pas sur la véracité du récit évangélique. Elle le prend pour ce qu'il est : une sorte de récit populaire comme les ethnographes ont l'habitude d'en recueillir, et son souci est de repérer les influences narratives et culturelles qui s'y sont croisées. Ces influences ont continué à s'exercer bien après l'écriture des Évangiles, se manifestant jusqu'à nos jours dans des récits et des thèmes iconographiques dont elle donne un riche aperçu.

2 Le récit évangélique emprunte à deux sortes de sources. Des sources vétérotestamentaires tout d'abord. Cette jeune fille à qui, parce qu'elle lui a plu au cours d'un banquet, un roi promet: «ce que tu me demanderas, je te le donnerai, 
jusqu'à la moitié de mon royaume » (Marc 6,23), n'est pas sans rappeler l'héroïne du livre d'Esther, à qui le roi Assuérus, séduit lui aussi au cours d'un banquet, fait mot pour mot la même promesse (Esther 5,3-6; 7,2; cité page 46). La première reçoit sur un plat la tête du Baptiste, la seconde obtient la mise à mort de Haman, le conseiller félon. Que Marc se soit souvenu du livre d'Esther parait d'autant plus probable que le titre de roi (basileús) qu'il décerne à Hérode est impropre : le tétrarque Hérode Antipas, que les Romains ont refusé de faire roi, n'a, à la lettre, aucun « royaume » à partager (46). Au livre d'Esther, il faut ajouter le Livre des Rois puisque, aussi bien chez Luc que chez Marc, le rapprochement entre Jean et Élie joue un rôle important dans la narration (34).

3 Mais l'auteur a débusqué une source d'une tout autre nature, et c'est là une remarquable trouvaille, à laquelle les exégètes seront désormais obligés de se référer. Relisons en effet Hérodote, au livre IX de ses Histoires (cité et commenté page 65sqq.). Le roi Xerxès a courroucé son épouse Amestris à cause d'un présent qu'il a fait à sa maîtresse Artaynté. Désireuse de se venger, l'épouse bafouée attend le banquet qui se tient une fois l'an, au jour anniversaire de la naissance du roi, car l'usage perse impose au monarque de satisfaire à toutes les demandes qui lui sont faites lors de ce banquet. Et là, elle demande qu'on lui livre Artaynté. Le roi est contraint de s'exécuter malgré son chagrin, laissant ainsi sa maîtresse aller à la mort. La parenté avec le récit évangélique est frappante. Hérodiade, tout comme Amestris, désire se venger d'une tierce personne, en l'occurrence Jean-Baptiste. Elle attend l'anniversaire de son époux, car elle sait que ce sera un " jour favorable » (Marc 14,11). Vient alors l'épisode où le roi promet à la fille d'Hérodiade de lui donner tout ce qu'elle demandera. Sur le conseil de sa mère, la jeune fille exige la tête de Jean-Baptiste. Et le roi, bien qu'attristé, ne peut pas la repousser, « à cause des serments et des convives ».

On accorde volontiers à l'auteur que, si « un modèle a bien exercé une influence sur le motif narratif de la demande contraignante au cours du banquet d'anniversaire d'Hérode, il parait difficile de ne pas le reconnaître dans Hérodote " (67). On ne sait trop par quelles voies un motif narratif perse a cheminé jusqu'en Palestine, mais on sait du moins que, depuis l'exil à Babylone, la culture perse a profondément influencé les juifs (ibid.). La dynastie iduméenne des Hérode avait pris l'habitude de célébrer avec faste les anniversaires des princes régnants, coutume qui n'avait pu venir de leurs sujets juifs car ceux-ci s'abstenaient rigoureusement de ces fêtes impies à leurs yeux. Même chez les Grecs, la célébration des anniversaires ne s'est généralisée qu'à l'époque hellénistique, à la faveur, semble-t-il, des contacts avec la Perse (65). On voit donc à quel point cette histoire de banquet d'anniversaire nous incite à porter nos regards vers la Perse.

Qu'en est-il maintenant de la jeune danseuse (dont l'Évangile ne donne pas le nom, et que la tradition a baptisée Salomé sur la foi de Flavius Josèphe, lequel ne parle pas de danse). Sur ce point, on comprendra mieux la démarche de l'auteur en prenant le livre par la fin, et en considérant les représentations de Salomé qui se répandent dans l'art chrétien à partir du IX siècle (169sqq.). De façon remarquable, et sans que rien dans le texte évangélique n'y ait incité les artistes, on la voit parfois danser comme une acrobate. Sur le tympan de la cathédrale de Rouen et sur un vitrail de la cathédrale de Bourges, elle marche sur les mains selon le modèle du kubistétère, jambes repliées comme si elle s'apprêtait à faire un saut périlleux. Ailleurs, elle est renversée tête en arrière dans l'attitude que l'école de Charcot a appelée l'arc hystérique (voir en particulier le psautier anglais conservé à la Bibliothèque nationale de Munich, et le 
vitrail de l'église Saint-Jean de Lyon, reproduits aux pages 176 et 177). Et là, elle n'est pas sans rappeler les malades atteints de ce qu'on appelait au Moyen Âge le mal de saint Jean, c'est-à-dire l'épilepsie (le Baptiste devait ce patronage au fait qu'on voyait alors dans la danse de Salomé la manifestation d'une crise d'épilepsie). Dans certaines régions, l'angoisse s'emparait dès le début du mois de juin de ces «danseurs de saint Jean ", qui attendaient avec impatience la vigile de la célébration de la naissance du Baptiste, espérant qu'ils seraient soulagés s'ils dansaient alors devant les autels du saint (134). La jeune danseuse du vitrail de Saint-Jean de Lyon et du psautier de Munich est donc bel et bien une épileptique. Elle fait aussi penser, nous dit l'auteur, à d'autres victimes d'un mal lui aussi saisonnier : les tarentulées de la Terre du remords (135sqq.). De fait, ces représentations de Salomé rappellent étonnamment les descriptions fameuses d'Ernesto de Martino.

Doit-on penser que les auteurs des Synoptiques avaient en tête des manifestations morbides de ce genre lorsqu'ils ont composé leur récit? L'auteur le pense, et les indices en ce sens ne sont pas négligeables. De Martino lui-même avait relié le tarentulisme au Corybantisme antique (163); d'autres auteurs à sa suite l'ont rapproché des diverses danses rituelles attestées dans l'Antiquité - danses qui prenaient parfois un caractère acrobatique et où l'on rencontrait déjà le pas du kubistétère. Rouvrant ce vaste dossier (83sqq.), C. Gauthier s'attarde en particulier sur les danses cathartiques auxquelles les jeunes filles d'Athènes ou d'autres cités grecques devaient se livrer lors de l'apparition des premières règles. La danse de Salomé pourrait être le souvenir de telles pratiques, ce qui lui enlèverait le caractère scabreux qui a étonné tant de commentateurs. Dans l'Évangile même, le thème est seulement suggéré par le fait que l'Iduméenne Salomé appartient à une race impure depuis son origine, que la tradition fait remonter à Ésaü. Mais il réapparait avec force dans l'iconographie médiévale, d'autant plus facilement que les symptômes de l'épilepsie ont été longtemps assimilés à ceux des jeunes filles nouvellement menstruées (254).

7 Quant à la décapitation de Jean, l'iconographie semble parfois l'apparenter à un sacrifice. Certaines représentations suggèrent même que ce sacrifice pourrait être suivi de la manducation de la victime. Ainsi, sur une gravure de Dürer reproduite à la page 248, Salomé et Hérodiade placent le chef du saint parmi les couverts et les reliefs du banquet. Dans un tableau du Flamand Quentin Matsys reproduit à la page 250, Hérodiade s'apprête visiblement à planter son couteau dans la tête du Précurseur, qu'on a déposée devant elle sur la table. Dans les Évangiles, moins lourdement affirmé, le caractère sacrificiel de la mort de Jean est tout de même présent par allusion: la décapitation du Précurseur annonce le sacrifice glorieux du Messie. Ce qu'un bréviaire d'York commente de façon lapidaire: "la tête de Jean désigne (signat) le Corps du Christ, dont nous nous nourrissons (quo pascimur) au saint autel» (cité page 238). Et le Baptiste présente en tout cas les attributs de la perfection qu'on exigeait des victimes sacrificielles puisque Luc en fait un homme consacré dès sa naissance, une manière de nazir (197sqq.)

8 Entre le Précurseur et le Messie, Luc s'attache d'ailleurs à construire une rigoureuse symétrie : ils naissent à six mois d'intervalle, ce que la tradition chrétienne a conservé en célébrant leurs naissances aux deux solstices opposés. L'un naît d'une femme réputée trop vieille pour enfanter, l'autre d'une vierge ; l'un est rempli du Saint-Esprit, l'autre est conçu du même Saint-Esprit. Pour C. Gauthier, cette opposition si complète les ramène à l'unité et en fait des quasi-jumeaux (207), gémellité qui s'accuse encore 
dans les traditions mandéennes et dans certains évangiles apocryphes (ibid., n. 4). Tout cela n'est pas sans évoquer les jumeaux ou quasi-jumeaux attestés ailleurs dans la Bible (pensons à Jacob et Ésaü) ou dans les innombrables récits qui, du bassin méditerranéen jusqu'à l'Inde, font de l'abaissement ou de la mort de l'un des jumeaux une condition nécessaire à l'exaltation de l'autre (208sqq.) L'Évangile de Jean est très explicite sur ce point quand il fait dire au Baptiste : «Il faut qu'il croisse et que je diminue. » (Jean 3,30, cité page 238), formule que Nicolas de Lyre prend au pied de la lettre : «... Jean a été diminué de la tête ; le Christ a été élevé en croix (exaltatus est in cruce) » (238).

Au croisement de l'exégèse, de l'histoire de l'art et de l'anthropologie religieuse, le beau livre de C. Gauthier est inclassable et fascinant. Il montre bien tout ce qu'un regard anthropologique peut, lorsqu'il est guidé par une érudition sans faille, apporter à notre compréhension du texte évangélique et des traditions chrétiennes. 